\title{
Reintroduction of Top-Order Predators: Using Science to Restore One of the Drivers of Biodiversity
}

\author{
Matt W. Hayward ${ }^{1}$ and Michael J. Somers ${ }^{2}$ \\ ${ }^{1}$ Mammal Research Institute, Polish Academy of Science \\ ${ }^{2}$ Centre for Wildlife Management, Centre for Invasion Biology, \\ University of Pretoria
}

Top-order predators is a broad phrase that we have intentionally chosen to describe carnivorous mammalian predators with a range of body sizes that occur at the upper end of the food chains of each continent. This definition is not limited by body mass or taxonomic clade, as it was intended to compare the actual or potential reintroduction of a diverse range of species from grey wolves, Canis lupus, to marsupial predators, such as Tasmanian devils, Sarcophilus harrisi.

By their very nature, top-order predators are relatively rare in natural ecosystems - be they African lions, Panthera leo, preying upon the vast herds of wildebeest, Connochaetes taurinus, in the Serengeti; wolves preying upon the large elk, Cervus elaphus, herds of Yellowstone; or dingoes, Canis lupus dingo, preying upon the millions of kangaroos in the Simpson Desert. This inherent scarcity lends itself to difficulty and insecurity in conservation efforts (Weber \& Rabinowitz, 1996), as small declines in already small populations can set into motion unpredictable and uncontrollable stochastic forces as part of the small-population paradigm (Caughley, 1994). 
While a range of threatening processes affect top-order predators (IUCN, 2007), ultimately they are mostly incompatible with human existence (Kruuk, 2002). Valuable attempts to integrate top-order predators into human landscapes are underway (e.g. Ogada et al., 2003) but, wherever pastoralism provides an easy source of meat for carnivores, the risk of human-wildlife conflict will remain (Treves \& Karanth, 2003). Since the advent of early hominids, there has been conflict (Brain, 1981) and competition for the top-order predator niche (Kruuk, 2002). Consequently, we have been present at, and often responsible for, the extinction of numerous large carnivores in Europe, North America, South America and Australia (Martin, 1967; Martin \& Guilday, 1967; Flannery, 1994; Flannery \& Roberts, 1999; Stuart, 1999). The number of carnivore species driven extinct during the Pleistocene was disproportionately high (Martin \& Steadman, 1999). Even today, those top-order predators that persist continue to be persecuted by humans-be they brown bears, Ursus arctos, in Europe (Gentleman, 2004; Hunter, 2006); snow leopards, Uncia uncia, in the Himalayas (Bagchi \& Mishra, 2006); or jaguars, Panthera onca, in Venezuela (Polisar et al., 2003). Direct persecution may not be the sole threat, as a decline in prey will invariably lead to a decline in predator abundance through bottom-up limitation (Karanth et al., 2004; Hayward et al., 2007d).

This simplification of the diverse threats to top-order predators may ultimately benefit their conservation. If scientists can successfully identify the key extinction threats to a species and agree upon them, they can work towards removing those threats. Where conservation biologists continue to disagree on the causes of endangerment of threatened species, little action can occur. Such disagreement between conservation practitioners may be the key to identifying why some countries have implemented numerous reintroduction programmes, while other countries have not bothered.

Top-order predators are amongst the most studied wild organisms on the planet, and we know the natural history of many species in great detail. Therefore, we have a deep understanding of their behavioural and evolutionary ecology (see Somers \& Gusset, this volume). As a consequence, there is general agreement as to the ultimate extinction threats facing many top-order predators, such that conservation management actions can be based on sufficient knowledge to achieve satisfactory conservation goals. Yet, despite popular perceptions to the contrary, other top-order predators are more difficult to study or have simply been neglected by researchers, resulting in insufficient 
ecological understanding to develop confidence in conservation management actions.

Reintroduction is one action available to conservation managers. Sadly, such actions can only occur after other conservation strategies have failed. Throughout this book, we define reintroduction as an attempt to establish a species within its historical range but where it has since been extirpated, and translocation as the deliberate movement of wild individuals between parts of their extant range (IUCN, 1998). Although top-order predators have declined globally (Weber \& Rabinowitz, 1996), they are still amongst the most frequently reintroduced group of organisms (Seddon et al., 2005). There are multiple reasons for this, including assisting with a species' conservation (Hayward et al., 2007a), the degree of knowledge about these charismatic species, the restoration of ecosystem functioning (Terborgh et al., 1999; Sinclair et al., 2003), the financial benefits of their presence in ecotourism ventures (Lindsey et al., 2005, and this volume), or that they were the first and only species to have been made locally extinct.

Determining the success of reintroductions is an essential practice. For most species, definitions of success include an unsupported, self-sustaining population of $>500$ individuals (Griffith et al., 1989) or a local categorization as vulnerable or better according to IUCN (International Union for the Conservation of Nature and Natural Resources) Red List criteria (Breitenmoser et al., 2001). Top-order predator populations that exceed 500 individuals are rare in today's world of fragmented landscapes. Indeed, the Vulnerable category of the IUCN Red List requires $>1000$ mature individuals (IUCN, 2001), which means that supposedly natural populations, such as the cheetahs, Acinonyx jubatus, of the Serengeti Plains ( 60 adult females, which are $25 \%$ more common than males) (Kelly et al., 1998), would be deemed unsuccessful had they stemmed from a reintroduction. Thus, in the short term, reintroduction success can be more satisfactorily defined as breeding by the first wild-born generation or a 3-year breeding population with natural recruitment exceeding mortality (Griffith et al., 1989), particularly in small, enclosed reserves (Hayward et al., 2007b). In all but the largest reserves, populations of top-order predators that are self-sustaining (i.e. that do not require some form of human interference such as genetic rescue) or exceed 500 individuals are likely to be very unusual (see Frankham, this volume; Gusset, this volume).

It is universally recommended that continuing, long-term monitoring should occur after reintroductions have taken place to ensure continued 
population growth or stability (Mills, 1991; Weber \& Rabinowitz, 1996; Hunter, 1998; Breitenmoser et al., 2001; Hofmeyr et al., 2003; Moehrenschlager \& Somers, 2004; Gusset, this volume). Furthermore, on-going management is also likely to be necessary to ensure survival of reintroduced stock, manage their increases or avoid genetic and other stochastic problems (Frankham, this volume; Gusset, this volume).

It is timely that this diverse array of conservation biologists collectively recorded their experiences, results and opinions regarding the reintroduction of top-order predators. There are plans to reintroduce tigers, Panthera tigris, to Sariska, India (Q. Qureshi, Wildlife Institute of India, Dehra Dun, India; personal communication), and a second population of Asiatic lions, Panthera leo persica, may soon be reintroduced to Madhya Pradesh (Johnsingh et al. 2007). The world's most endangered canid, the Ethiopian wolf, Canis simiensis, will also soon be reintroduced to parts of its former range to reduce the risk associated with catastrophes striking its few remaining sanctuaries (C. Sillero-Zubiri, University of Oxford, UK; personal communication).

But what of other top-order predators? Will Tasmanian devils that are currently being decimated by facial tumour cancer ever be returned to the Australian mainland, despite existing there as little as 450 years ago (Butler, 1968)? And what about the eastern quoll, Dasyurus viverinus, which was last observed on the Australian mainland in the 1960s (Strahan, 1995)? Poland's Białowieża Primeval Forest is the most pristine example of the mixed deciduous forests that once covered most of continental Europe, but the absence of brown bears illustrates that this area is not completely intact (Jędrzejewska et al., 1995; Clark, this volume). Can this species potentially be reintroduced successfully, considering that the attempts made prior to the 1960s failed (Clark, this volume)?

This book aims to identify the top-order predators that have been studied sufficiently for conservation managers to have confidence in attempting reintroductions, and those for which we need more information. For those species that are frequently reintroduced, the book will identify the information that is essential to give confidence in achieving a successful reintroduction. The book will also identify those top-order predators that are rarely reintroduced and will determine whether the absence of reintroduction is due to insufficient ecological knowledge of the species or to a lack of need for reintroduction.

For example, recent reviews of carnivore reintroductions (Breitenmoser et al., 2001) illustrated great disparities between the reintroduction of top- 
order predators. It is notable that five African top-order predators have been reintroduced during 30 projects, while two Asian species have been reintroduced in just two projects. In North America, six species have been reintroduced in 28 projects (Breitenmoser et al., 2001).

In order to achieve these goals, the book is broken up into three sections. The first section provides reviews of reintroduction programmes of wolves, bears, African lions, African wild dogs (Lycaon pictus), tigers, snow leopards, leopards (Panthera pardus), jaguars and cheetahs. The second section provides reviews of the ecology of individual species, which highlight that there is no current need for reintroduction to occur. This may be because existing populations are able to recolonize vacant habitats naturally; because a species still exists throughout its range, albeit at dangerously low densities; or because we lack a sufficient understanding of the species ecology to risk such a programme. The final section provides examples of recent advances in our understanding of top-order predator ecology that should enable us to predict their behavioural or ecological responses to the reintroduction process.

This book is not intended to describe the methods by which a reintroduction programme should be undertaken, as there are many publications available that provide this information (Hofmeyr \& van Dyk, 1998; Bothma, 2002). Rather, we hope this book will highlight recent advances in our understanding of top-order predator behavioural and evolutionary ecology that improve the likelihood of success of reintroduction programmes, or highlight deficiencies that require further research.

If nothing else, we hope this book will illustrate the necessity of a detailed understanding of the basic natural history of species from sites throughout their range and in different time periods. Without such knowledge, scientists can have little confidence in recommending a conservation strategy to managers. Such simple natural history is largely spurned by the scientific, or perhaps just the academic, world (Wilcove \& Eisner, 2000), but is fundamental to the successful conservation of threatened species (Belovsky et al., 2004). Indeed, the 31 researchers who continued to describe the diet of the lion following the first description (Bourliere, 1963) provided essential information that resulted in an ability to predict the diet of lions at reintroduction or at unstudied sites (Hayward et al., 2007c). Similarly, multiple publications assessing reintroductions and translocations of wild dogs have yielded substantial breakthroughs in our understanding of the essential requirements for a successful reintroduction (Gusset et al., 2008). Repeated descriptions of the natural history of a species in different ecosystems and in different times 
(seasons, years, climatic variations) provide the necessary replication to yield causal explanations to the theoretical complexities of conservation ecology (Belovsky et al., 2004).

Large-scale, replicated and controlled manipulation experiments are far more attractive to the academic world, however top-order predators, particularly those that require reintroduction, are largely incompatible with such actions given the small sample sizes of sites or individuals that are often available. It is rare that a reintroduction programme is designed as an appropriately replicated experiment, but increasing cooperation between researchers and managers may see this occurring more frequently. Furthermore, new modelling techniques enable us to use a limited amount of data and then to simulate replicated reintroduction experiments (e.g. Gusset, this volume). We hope this book will illustrate that conservation scientists must persist in describing the natural history of threatened species in the knowledge that this is an essential requirement of successful conservation management. Given the high frequency of reintroduction programmes occurring in some places (Hayward et al., 2007b), there may now be opportunities to consolidate the research via some post hoc meta-analysis to further establish and refine the emerging science of reintroduction biology.

\section{Acknowledgements}

This book is a result of a symposium held during the annual conference of the Society for Conservation Biology held in Port Elizabeth, South Africa, in July 2007. We thank the Society for providing financial support for many of our presenters. We thank Elissa Cameron and Markus Gusset for commenting on earlier drafts of this chapter.

\section{References}

Bagchi, S. \& Mishra, C. (2006) Living with large carnivores: Predation on livestock by the snow leopard (Uncia uncia). Journal of Zoology 268, 217-224.

Belovsky, G.E., Botkin, D.B., Crowl, T.A. et al. (2004) Ten suggestions to strengthen the science of ecology. BioScience 54, 345-351.

Bothma, J.D.P. (2002) Game Ranch Management (Fourth Edition). van Schaik, Pretoria. 
Bourliere, F. (1963) Specific feeding habits of African carnivores. African Wildlife 17, 21-27.

Brain, C. (1981) The Hunters of the Hunted? An Introduction to African Cave Taphonomy. University of Chicago Press, Chicago, USA.

Breitenmoser, U., Breitenmoser-Wursten, C., Carbyn, L.N. \& Funk, S.M. (2001) Assessment of carnivore reintroductions. Carnivore Conservation. (eds J.L. Gittleman, S.M. Funk, D.W. Macdonald \& R.K. Wayne), pp. 241-280. Cambridge University Press and The Zoological Society of London, Cambridge.

Butler, W.H. (1968) Remains of Sarcophilus the "Tasmanian” Devil (Marsupialia, Dasyuridae) from coastal dunes south of Scott River, Western Australia. The Western Australian Naturalist 11, 87-89.

Caughley, G. (1994) Directions in conservation biology. Journal of Animal Ecology 63, 215-244.

Flannery, T.F. (1994) The Future Eaters: An Ecological History of the Australasian Lands and People. Reed Books, Sydney.

Flannery, T.F. \& Roberts, R.G. (1999) Late Quaternary extinctions in Australasia: An overview. Extinctions in Near Time. (ed R.D.E. MacPhee), pp. 239-255. Kluwer Academic/Plenum Publishers, New York.

Gentleman, A. (2004) Bavaria's bear exterminated. The Guardian p. 22. London, UK.

Griffith, B., Scott, J.M., Carpenter, J.W. \& Reed, C. (1989) Translocation as a species conservation tool: Status and strategy. Science 245, 477-480.

Gusset, M., Ryan, S.J., Hofmeyr, M. et al. (2008) Efforts going to the dogs? Evaluating attempts to re-introduce endangered wild dogs in South Africa. Journal of Applied Ecology 45, 100-108.

Jędrzejewska, B., Bunevich, A.N. \& Jędrzejewski, W. (1995) Observation of brown bear Ursus arctos in Bialowieża Primeval Forest from 1948-1950. Parki Narodowe i Rezerwaty Przyrody 14, 87-90.

Johnsingh, A.J.T., Goyal, S.P. \& Qureshi, Q. (2007) Preparations for the reintroduction of Asiatic lions Panthera leo persica into Kuno Wildlife Sanctuary, Madhya Pradesh, India. Oryx 41, 93-96.

Kruuk, H. (2002) Hunter and Hunted. Cambridge University Press, Cambridge.

Hayward, M.W., Adendorff, J., O'Brien, J. et al. (2007a) Practical considerations for the reintroduction of large, terrestrial, mammalian predators based on reintroductions to South Africa's Eastern Cape Province. The Open Conservation Biology Journal 1, 1-11.

Hayward, M.W., Adendorff, J., O’Brien, J. et al. (2007b) The reintroduction of large predators to the Eastern Cape Province, South Africa: An assessment. Oryx 42, 205-214. 
Hayward, M.W., Hofmeyr, M., O’Brien, J. \& Kerley, G.I.H. (2007c) Testing predictions of the prey of the lion (Panthera leo) derived from modelled prey preferences. Journal of Wildlife Management 71, 1567-1575.

Hayward, M.W., O’Brien, J. \& Kerley, G.I.H. (2007d) Carrying capacity of large African predators: Predictions and tests. Biological Conservation 139, 219-229.

Hofmeyr, M. \& van Dyk, G. (1998) Cheetah introductions to two north-west parks: Case studies from Pilanesburg National Park and Madikwe Game Reserve. Cheetahs as Game Ranch Animals. (ed B.L. Penzhorn), pp. 60-71. Wildlife Group of the South African Veterinary Association, Onderstepoort.

Hofmeyr, M., Davies, R., Nel, P. \& Dell, S. (2003) Operation Phoenix-The introduction of larger mammals to Madikwe Game Reserve. Madikwe Game Reserve: A Decade of Progress. (ed M. Brett), pp. 8-20. North West Parks \& Tourism Board, Rustenburg.

Hunter, L.T.B. (1998) Early post-release movements and behaviour of reintroduced cheetahs and lions, and technical considerations in large carnivore restoration. Cheetahs as Game Ranch Animals. (ed B. L. Penzhorn), pp. 72-82. Wildlife Group of the South African Veterinary Association, Onderstepoort.

Hunter, X. (2006) Hunters kill France's last brown bear. The Guardian. London, UK.

IUCN (1998) IUCN Guidelines for Re-introductions. IUCN, Gland, Switzerland.

IUCN (2001) IUCN Red List Categories and Criteria: Version 3.1. IUCN, Gland, Switzerland.

IUCN (2007) 2007 Red List of Threatened Species. IUCN, Gland, Switzerland.

Johnsingh, A.J.T., Goyal, S.P. \& Qureshi, Q. (2007) Preparations for the reintroduction of Asiatic lions Panthera leo persica into Kuno Wildlife Sanctuary, Madhya Pradesh, India. Oryx 41, 93-96.

Karanth, K.U., Nichols, J.D., Kumar, N.S., Link, W.A. \& Hines, J.E. (2004) Tigers and their prey: Predicting carnivore densities from prey abundance. Proceedings of the National Academy of Science, USA 101, 4854-4858.

Kelly, M.J., Laurenson, M.K., Fitzgibbon, C.D. et al. (1998) Demography of the Serengeti cheetah (Acinonyx jubatus) population: The first 25 years. Journal of Zoology 244, 473-488.

Lindsey, P.A., Alexander, R.R., du Toit, J.T. \& Mills, M.G.L. (2005) The potential contribution of ecotourism to African wild dog Lycaon pictus conservation in South Africa. Biological Conservation 123, 339-348.

Martin, P.S. (1967) Prehistoric overkill. Pleistocene Extinctions: The Search for a Cause. (eds P.S. Martin \& H.E. Wright), pp. 75-120. Yale University Press, New Haven.

Martin, P.S. \& Guilday, J.E. (1967) A bestiary for Pleistocene biologists. Pleistocene Extinctions: The Search for a Cause. (eds P.S. Martin \& H.E. Wright), pp. 5-66. Yale University Press, New Haven. 
Martin, P.S. \& Steadman, D.W. (1999) Prehistoric extinctions on islands and continents. Extinctions in Near Time. (ed R.D.E. MacPhee), pp. 17-55. Kluwer Academic/Plenum Publishers, New York.

Mills, M.G.L. (1991) Conservation management of large carnivores in Africa. Koedoe 34, 81-90.

Moehrenschlager, A. \& Somers, M.J. (2004) Canid reintroductions and metapopulation management. Canids: Foxes, Wolves, Jackals and Dogs. Status Survey and Conservation Action Plan. (eds C. Sillero-Zubiri, M. Hoffman \& D.W. Macdonald), pp. 289-298. IUCN/SSC Canid Specialist Group, Gland, Switzerland.

Ogada, M.O., Woodroffe, R., Oguge, N.O. \& Frank, L.G. (2003) Limiting depredation by African carnivores: The role of livestock husbandry. Conservation Biology 17, 1521-1530.

Polisar, J., Maxit, I., Scognamillo, D., Farrell, L., Sunquist, M.E. \& Eisenberg, J.F. (2003) Jaguars, pumas, their prey base, and cattle ranching: Ecological interpretations of a management problem. Biological Conservation 109, 297-310.

Seddon, P.J., Soorae, P.S. \& Launay, F. (2005) Taxonomic bias in reintroduction projects. Animal Conservation 8, 51-58.

Sinclair, A.R.E., Mduma, S.A.R. \& Brashares, J.S. (2003) Patterns of predation in a diverse predator-prey system. Nature 425, 288-290

Strahan, R. (1995) Mammals of Australia. Reed Books, Sydney.

Stuart, A.J. (1999) Late Pleistocene megafaunal extinctions: A European perspective. Extinctions in Near Time. (ed R.D.E. MacPhee), pp. 257-270. Kluwer Academic/ Plenum Publishers, New York.

Terborgh, J., Estes, J.A., Paquet, P. et al. (1999) The role of top carnivores in regulating terrestrial ecosystems. Continental Conservation: Scientific foundations of Regional Reserve Networks. (eds M.E. Soule \& J. Terborgh), pp. 39-64. Island Press, Washington, DC.

Treves, A. \& Karanth, K.U. (2003) Human-carnivore conflict and perspectives on carnivore management worldwide. Conservation Biology 17, 1491-1499.

Weber, W. \& Rabinowitz, A. (1996) A global perspective on large carnivore conservation. Conservation Biology 10, 1046-1054.

Wilcove, D. \& Eisner, T. (2000) The impending extinction of natural history. The Chronicle of Higher Education 15 September. 